\section{TIP OF THE ISSUE}

Dear Ediror.

Qometimes as in cases of burns, during mastectomy or any other Sprocedure on the arm, only other arm of the patient is available for various activities like IV infusion, recording blood pressure, pulse oximetry etc. Recording blood pressure and running intravenous line on the same arm then is tricky. Back flow of the fluid and sometimes blood occurs when the cuff of sphygmomanometer is inflated. This can be easily avoided by passing the intravenous line ubing between the layers of the sphygmomanometer cuff. Inflating the caff will kink the line and block the back flow. The flow of the fluid wilt restart on deflating the cuff (Fig. 1).

Lt Col S GOKHALE

Classified Specialist (Pathology \& Microbiology). Command Hospital (Central Command). Lucknow - 226002.

\section{TECHNOLOGY UPDATE - PINLESS FIXATOR}

Dear Editor,

7 This is with reference to the article published in MJAFI $200 \mathrm{t} ; 57$ :

234-6 by Lt Col S Chaw la. The article has been written well and is very usefu] to junior surgeons in the peripheral hospitals. I would like to add a few practical aspects for the application of Pinless Fixator.

\section{Selection of Clips :}

(a) A minimum of 4 clips ( 2 in each major fragment) should be used to achieve and maintain reduction.

(b) Smallest available clip in each category should be used, which will accornmodate the anatomy of the leg. for maximum stability of the frame.

\section{Application of the Clips}

(a) Clips are placed according to the same principles (safe corridors) as for the external fixation to prevent neurovascular damage.

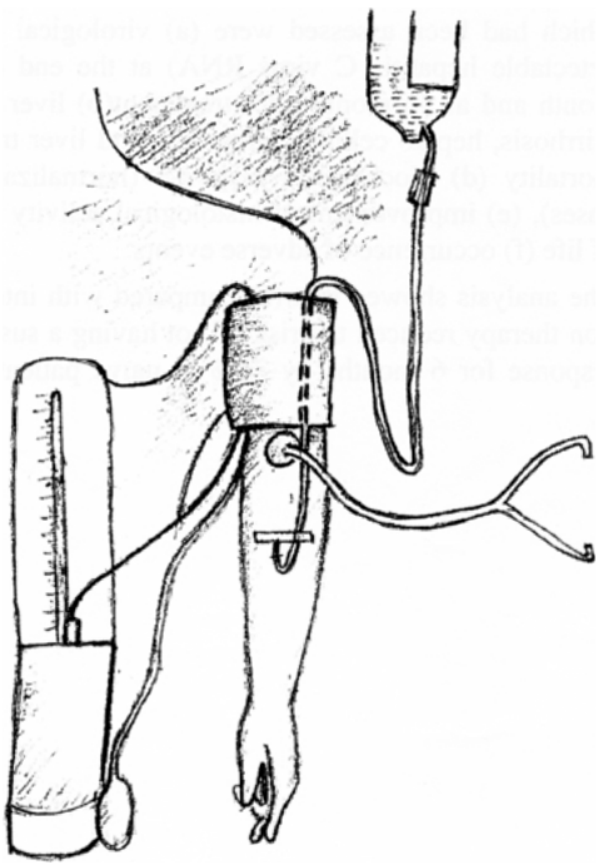

Fig. 1 :

(b) Asymmetrical clip should not be applied by rocking movement as done for symmetrical clip. It may be necessary to wiggle it slightly to ensure entry into the bone cortex. If rocking is done it will damage the anterior tibial crest because of the two prongs.

\section{Frame Assembly}

Only one bar should be used on all clips. Use of a second bar on all clips may cause malalignment and/or clip slippage.

\section{Maj JASWINDER SINGH}

Graded Specialist (Surgery), 169 Military Hospital, C/o 56 APO.

\section{REPLY}

Dear Editor.

T am thankful to Major Jaswinder Singh for reading the article with linterest and sending his suggestions regarding application of pinless extemal fixator. All the details regarding selection of clips, application of clips and frame assembly are already included in the article. These practical points will help the surgeons in peripheral hospitals to master the technique of application.

Regarding frame assembly, $I$ do not agree with him as it is not possible to use two bars, as the system is designed for only one carbon fibre bar to be used in all clips. Carbon fibre rod should be of adequate length and diameter depending upon the age of the patient and length of the tibia. It remains an excellent ideal tool for emergency management of compound fracture shaft tibia and fibula in a peripheral setup especially in polytrauma patients. The main advantage of the pinless external fixutur is to avoid further contamination of the medullary canal in compound fractures of the tibia as it uses trocar tipped clamps to grip the outer tibial cortex rather than pins to transfix it as seen in conventional external fixators [1]. This system can be applied without the aid of electrical equipment such as power drilis for bone screw insertion or image intensifiers to facilitate bone alignment [2]. Evacuation to referral hospital is easier with the pinless fixator if considered necessary in polytrauma patients requiring superspecialist care.

\section{References}

1. Thomas SR, Giele H. Simpson AH. Advantages and disadvantages of pinless external tixation. Injury 2000:31(10):805-9.

2. Gardener TN, Simpson H. Kenwright J. Rapid application fracture fixators - an evaluation of mechanical performance. Clin Biomech $2(0) 1: 16(2) ; 151-9$.

Lt Col S CHAWLA

Classifjed Specialist (Surgery), Military Hospital, Bhopal - 31 . 